\title{
IJQSES $=$
}

Sayı 16, Aralık 2021 \& No 16, December 2021

\section{Üniversite Personelinin Afet Yönetimi Hakkında Bilgi, Tutum ve Davranışlarının İncelenmesi: Çanakkale Onsekiz Mart Üniversitesi Örneği}

\section{Examination of University Personnel's Knowledge, Attitudes and Behaviors about Disaster Management: The Example of Çanakkale Onsekiz Mart University}

$\begin{array}{cc}\begin{array}{c}\text { Çağlar Bulat } \\ \text { Uzman }\end{array} & \begin{array}{c}\text { Durmuş Özbaşı } \\ \text { Doç. Dr. }\end{array} \\ \text { Sağlık Bakanlığı } & \text { Çanakkale Onsekiz Mart Üniversitesi } \\ \text { dozbasi@ gmail.com } \\ \text { caglarbulat84@ gmail.com } & \text { ORCID ID: 0000-0001-5078-477X } \\ \text { ORCID ID: 0000-0002-8833-3357 } & \\ & \end{array}$

\section{Makale Bilgisi / Article Information}

Makale Türü / Article Type : Araştırma Makalesi

Geliş Tarihi / Received : 17 Eylül 2021

Kabul Tarihi / Accepted : 13 Ekim 2021

Yayın Tarihi / Published : 15 Aralık 2021

DOI Number : 10.20860/ijoses.996847

"Bu makale Doç. Dr. Durmuş ÖZBAŞI danışmanlığında Çağlar BULAT tarafindan hazırlanan "Üniversite personelinin afet yönetimi konusunda bilgi, tutum ve davranışlarının incelenmesi: Çanakkale Onsekiz Mart Üniversitesi örneği"

başlıklı yüksek lisans tezinden hazırlanmıştır. Ayrıca bu araştırma Çanakkale Onsekiz Mart Üniversitesi BAP birimince desteklenmiştir. Proje No: SYL-2019-2958”

$$
\text { * }
$$

\section{Kaynak Gösterme / Citation}

Bulat, Ç. \& Özbaşı, D. “Üniversite Personelinin Afet Yönetimi Hakkında Bilgi, Tutum Ve Davranışlarının İncelenmesi: Çanakkale Onsekiz Mart Üniversitesi Örneği ". Uluslararası Sosyal ve Eğitim Bilimleri Dergisi, 16 (2021): 68-82. 


\title{
Üniversite Personelinin Afet Yönetimi Hakkında Bilgi, Tutum ve Davranışlarının İncelenmesi: Çanakkale Onsekiz Mart Üniversitesi Örneği
}

\author{
Examination of University Personnel's Knowledge, Attitudes and Behaviors about Disaster \\ Management: The Example of Çanakkale Onsekiz Mart University
}

\section{Çağlar Bulat \& Durmuş Özbaşı}

$\ddot{O} z$

Doğada kendiliğinden olan ve herhangi bir zarara yol açmayan olaylar; insanların doğal alanları tahrip etmesi, nüfusun hızla artarak yeryüzünde kontrolsüzce yayılmaları afet kavramının oluşmasına sebebiyet vermiştir. Afetlerin zararlarına karşı insanoğlunun en büyük uygulamalarının başında ise hiç şüphesiz bilgi birikimi ve eğitim gelmektedir. Afet eğitimi konusunda en üst düzey eğitimi verebilecek yerlerin başında üniversiteler gelmektedir. Gerçekleştirilen bu çalışma ile üniversite bünyesinde görevli akademik ve idari personelin afete ne denli hazır olduklarını ölçmek, afet yönetimi konusuna hazırıkları sınanmak istenmiştir. Araştırmanın katılımcılarını üniversitede görevli akademik ve idari personel oluşturmaktadır. Araştırmaya toplam 1693 kişi katılıışır. Katılıma göre evrenin yaklaşık \% 68'ine (Evren=2491) ulaşılmıştır. Katılımcıların yaklaşık \%86'sı akademik, \%14'ü idari personelden oluşmaktadır. Gerçekleştirilen bu çalışmanın sonucunda; üniversite de görevli akademik ve idari personelin afetlere hazılık bilgi düzeyinin orta seviyede oldukları sonucuna ulaşımışır. İdari personelin hazırlık bilgi düzeyi ile davranış düzeyi akademik personellerin bilgi ve davranış düzeylerinden daha yüksek olduğu ortaya çıkmış olup tutum seviyelerinde herhangi bir farklılık tespit edilmemiştir. Personelin yaş seviyesi arttıkça afetlere hazırlık bilgi seviyesinde bir artışın olduğu ve bu artışın sebeplerinden birinin alınan afet eğitimi olduğu tespit edilmiştir.

Anahtar Kelimeler: Sağlık Hizmetleri, Afet Yönetimi, Bilgi, Tutum ve Beceri.

\section{Abstract}

The spontaneous occurrences that do not cause any harm in nature, the destruction of natural areas by humans and the rapid increase of the population and its uncontrolled spread on the earth have led to the emergence of the concept of disaster. Knowledge and education are undoubtedly the leading biggest practices of human beings against the harms of disasters. Universities are the leading places that can provide the highest level of education in disaster training. With the study conducted, it was aimed to measure how ready the academic and administrative personnel in the university are for a disaster and to test their preparations for disaster management. The participants of the research consisted of the academic and administrative personnel working at university. In the research, the number of participants was 1693. Considering the participation, 68 percent of the population was reached. $86 \%$ of the participants consisted of academic personnel, and $14 \%$ were comprised of administrative personnel. It was revealed that the level of knowledge of preparedness and behavioral levels of the administrative personnel were determined to be higher than those of the academic personnel, and no difference was found in their levels of attitude. It was discovered that there was an increase in the level of knowledge about preparedness for disasters as the ages of the personnel increased, and the received disaster training was found to be one of the causes of this increase.

Keywords: Health Services, Disaster Management, Knowledge, Attitude and Skill. 


\section{Extended Summary}

\section{Purpose and Significance:}

Natural events which are spontaneous and cause no harm; the destruction of natural spaces by humans, the rapid increase in population, and their uncontrolled spread over the earth have led to the notion of disaster. Disaster is a problem that must be managed. In this context, disaster management can be defined as a management process including gathering information, developing plans, taking and implementing necessary measures, coordinating the process, determining deficiencies by inspecting each step, and using all the opportunities and resources effectively by the community to understand the disasters' nature and to prevent minimize their damages. The management process is a non-uniform and dynamic process. Besides the fact that the knowledge of the manager is important, it is necessary to apply it to the people who are managed and to those who apply it, especially in disaster management. For the disaster management system to function properly, first of all, plans must be made, and if there are plans, those who will implement them must be trained in this regard. Training received before the disaster can help people cope with the post-disaster process. Disaster training should be as sustainable as necessary for disaster awareness training and dissemination of disaster culture in society. In Turkey, disaster education was first taught to secondary school students in 1992 by the Ministry of National Education (MEB) as an elective course under the name "Environment and Human". Currently, disaster education is provided in our country by different institutions and voluntary organizations. (Ünal ve Dımş1k1, 1999: 142-154) Universities are at the forefront of places that can provide the highest level of disaster education. In this context, it is very important to reveal the levels of preparedness of instructors for disaster management and to examine the levels of knowledge, attitude, and behaviour of individuals working in universities with comparative analyses.

\section{Methodology:}

This study was designed in a scanning model to present an existing situation as it is. The general scanning model includes the scanning methods that will be made on each of the individuals that make up the universe which is formed by a large number of people to make a general judgment about the universe in general terms. According to the 2018 data of the initiation date of the study, 1693 people were reached out of the total population of 2491. The data obtained according to the whole universe of the research was realized as $68 \%$. In the process of obtaining the data, a face-to-face data collection method from the volunteer individuals was chosen. The first part of the scale includes the items for the variable of age, gender, education level, and receiving disaster management education which is likely to affect the attitudes of academic and administrative staff working at the university on emergency and disaster management. In the second part, "The Knowledge, Attitude and Behaviour Scale about Disaster and Emergency Situation", which Kiraz (2008: 97) used in his thesis to determine the attitudes of university staff towards emergency and disaster management, consisting of 3 sub-dimensions and 38 questions in a 5-point Likert type was used. Anova, t-test, and Mann Whitney U tests were used to answer the sub-problems in the analysis of the data.

\section{Results, discussion and conclusion:}

According to the descriptive results obtained from the research, it was revealed that the disaster preparedness level of the university staff was $\left(X^{-}=2.72\right)$. As a result of a similar study conducted in Erzincan in 2014, it was determined that people's level of disaster preparedness knowledge was insufficient. According to this result, it can be deduced that this level is not sufficient in our country where disasters occur every year. A significant difference was found between the disaster preparedness knowledge levels of academic and administrative staff who participated in the study, and it was concluded that the knowledge level of the administrative staff $\left(X^{-}=2.87\right)$ was higher than the knowledge level of the academic staff $\left(\mathrm{X}^{-}=2.66\right)$. In Çelebi's study (2014), it was concluded that the staff who 
graduated from high school have higher knowledge levels about earthquakes. When it is examined whether there is a difference between the level of disaster preparedness knowledge according to their educational status; it was determined that the highest level of knowledge was in the undergraduate $\left(X^{-}=2.91\right)$ education level, and it was concluded that the lowest level of education was composed of the staff at the graduate $\left(\mathrm{X}^{-}=2.58\right)$ education level. Again, in a similar study, it was revealed that the level of preparedness against earthquakes was higher for the staff who graduated from high school. In the study conducted for Turkey, it was concluded that there is an increase in the level of consciousness of people with the increase in the level of education. When the disaster preparedness knowledge level of the university staff who received or did not receive disaster education was examined, it was found that the knowledge level of the people who received disaster education was higher than those who did not receive any training. In a study conducted in Gümüşhane, it was concluded that disaster education provided a positive increase in people's knowledge levels. It was investigated whether there was a difference between the level of attitude of people who had experienced or not experienced disasters before, and no significant difference was found. According to a study, it has been revealed that people who are exposed to disasters participate more in disaster education and have a higher rate of having a first aid kit at home. Accordingly, it can be concluded that exposure to disasters increases the level of preparedness of people for disasters. In this study, the average score regarding the time of disaster behaviour levels of university staff was 2.66. A similar result revealed that the level of disaster preparedness of the nurses working in the hospital with a doctorate education level was lower than those with other education levels. Again, according to the results of this study, it was determined that the disaster behaviour levels of people who were exposed to disasters before were higher. In a study conducted in their countries (Thailand and the Philippines), they determined that there was a positive increase in the disaster preparedness and the behaviour of the people who were exposed to disasters at the time of the disaster.

\section{Giriş}

İnsanların tabiattaki alanları tahrip etmesi, yeryüzünde hızla artan nüfus yoğunluğu, kendiliğinden doğada olan ve herhangi bir zarara yol açmayan doğa olaylarının afete dönüşmesine ve afet kavramının oluşmasına sebep olmuştur. Afet; insanın bedensel, ekonomik, sosyal ve kültürel çevresine zarar veren, normal yaşamı tamamen etkileyen veya yavaşlamasına neden olan, etkilenen kesimin kendi imkânları ile mücadele edemediği, kriz ortamının oluşmasına neden olan, doğal olarak veya insan etkisi ile oluşan durumlara verilen genel bir kavram olarak tanımlanabilir (Kadığlu ve Özdamar, 2011: 121). Afete ilişkin farklı tanımlar olmakla birlikte, tüm dünyada kullanılan afet tanımlarının ortak noktaları da bulunmaktadır. Afet tanımlarının ortak noktalarından yola çıkarak Kemaloğlu afet özelliklerini aşağıdaki gibi sıralamıştır(Kemaloğlu, 2015: 126-147):

- Doğadaki tüm canlıları etkileyebilmektedir,

- Bir tetikleyicisi mevcuttur, Afet ve zarar görebilirlik arasında doğrudan bir bağ bulunmaktadır,

- Oluşturduğu etkinin bertaraf edilmesinde kaynak yetersizliği vardır,

- Doğrudan insanı etkilediğinden toplumla yakın ilişkilidir.

Afetler, kendi içerisinde bir sistematik gerektirdiğinden yönetilmesi gereken sorunlardan biridir. Buna göre afet yönetimini, afetlerle oluşan zararın en aza indirilmesi veya önlenmesini amaçlamaktadır. Afetin yapısını anlamak amacıyla önce bilgi toplanması, plan yapılması veya geliştirilmesi, gerekli olan önlemlerin alınıp işlevsel hale getirilmesi ve sürecin yönetilmesi, mevcut tüm kaynakların hızlı ve etkili bir şekilde kullanılmasını içeren bir süreç olarak tanımlamak mümkündür (Afet ve Acil Durum Yönetimi Başkanlığı [AFAD], 2014a: 101). Yönetim süreci hızlı bir dinamiği olan ve her an değişkenlik gösterebilen bir süreçtir. Afeti yönetenlerin bilgi birikimi ve olaya hakim olması kadar, sürece destek verenlerin de bu konuda eğitimli olmaları önemlidir. Afet yönetim sürecinin düzgün işleyebilmesi ve 
sistemin kusursuz yürüyebilmesi, öncelikle planların yapılması ve bu planları yürütecek olanların da eğitilmesi sürecin sağlıklı ilerleyebilmesi açısından son derece önemlidir.

Afetlerle mücadelede, eğitimin önemi oldukça yüksektir. Çünkü eğitimli bireyler afet sırasında nasıl davranılması gerektiğini veya nelerin hangi sırayla yapılması gerektiği konusunda afet eğitimi aldıktan sonra çok daha etkili ve uygun bir şekilde uygulayabilirler. Deneyim, uzmanlık ve bilgi afetlerle mücadele ve afete hazırlık için önemli bileşenlerdendir. Toplumun da afetler konusunda kendi üzerine düşen görev ve sorumlulukları üstlenmesi için bu konuda bilince sahip olması şarttır. Afetlere karş1 bilinçli bir tutum geliştirmek ve buna uygun olarak davranmak için afetler ve diğer acil durumlar ile ilgili bilgi sahibi olanların afetler konusunda ne yapması gerektiğini ve hangi adımları atmaları gerektiğini bilmeleri gereklidir. Bu nedenle afetler ile ilgili alınması gereken önlemler veya eşyaların sabitlenmesi, acil durum çantalarının hazırlanması gibi afet öncesi yapılması gerekenler bireylerin davranışlarını etkileyecektir (Kiraz, 2018: 46). Bireylerin afete ilişkin tutumu, bilgisi ve davranışları afete uygun bir şekilde geliştiğinde ve güçlü olduğunda, toplumların da afetten en az düzeyde zarar görmesi veya hiç zarar görmemesi mümkündür. Bu bağlamda, bireylerin afetlere ilişkin hazırbulunuşluk düzeylerinin yüksek olması oldukça önemlidir. Bu kapsamda afet eğitimlerinin yaygınlaştırılması, kamu spotlarının oluşturulması, tatbikatlar ve benzeri çalışmaların yapılması bireylerin afete ilişkin tutumlarında pozitif yönde gelişmelerin oluşmasına katkı sunabilecektir. Ancak bu durumun sürdürülebilir olabilmesi ve toplumda afet kültürünün oluşabilmesi için afet eğitimlerinin ve diğer bilgilendirici notların devamlılığının olması gerekmektedir. Türkiye'de afet eğitimi ilk kez 1992 yılında Milli Eğitim Bakanlığı (MEB) tarafından ortaokul talebelerine "Çevre ve İnsan" adı altında seçmeli ders şeklinde başlamıştır. Afet eğitimi ülkemizde farklı kurum ve gönüllü organizasyonlar ile ülkemizde verilebilmektedir (Ünal ve Dımşıkı, 1999: 142-154). Afet eğitimi konusunda en üst düzey eğitimi verebilecek yerlerin başında üniversiteler gelmektedir. Bu yüzden üniversite öğretim elemanlarının afetler ile ilgili hazırlık düzeylerinin incelenmesi oldukça önemlidir.

\section{Afet Kavramı}

Türkçe'ye Arapça' dan geçmiş olan afet kelimesi “çeşitli doğa olaylarının sebep olduğu yıkım”, "çok kötü" veya "yıkım" gibi anlamlara gelebilmektedir (Türk Dil Kurumu, 2020). İngilizcede ise "disaster" kelimesi ile ifade edilmektedir. Kadıŏglu ve Özdamar(2011) ise afeti, eldeki imkan ve güç ile baş edilemeyen, tüm canlıları için can, mal ve sosyal kayıplara neden olabilen, normal yaşantıda aksaklıklara neden olan her türlü doğa veya insan kaynaklı olaylar olarak tanımlamaktadır. Afetlerin zararlı etkilerini yok etmek veya en aza indirmek için mevcut imkanların ve kaynakların etkili ve olması gerektiği şekilde kullanımı için afet kültürü ve eğitiminin yaygın ve devamlı hale getirilmesi şarttır. Bir başka ifadeyle afetler, birçok kurum veya kuruluşun birlikte hareket etmesini gerektiren, canlılar için sosyal ve fiziksel kayıpların oluşmasına neden olabilen, insan yaşantısını doğrudan veya dolaylı olarak etkileyebilen veya durdurabilen, hatta toplumsal yaşantıda kesintilere neden olabilen, teknoloji, insan veya doğa kaynaklı olaylardır. Bu olayların afet olarak tanımlanabilmesi için can ve mal kaybının oluşması gereklidir (Şahin ve Sipahioğlu, 2002).

Afetlerin sahip olduğu ortak özellikler şunlardır (Kadıŏlu ve Özdamar, 2011) :

- İnsanları ve doğadaki canlıları etkiler.

- Genel bir tehlikeye bağlı olarak oluşur.

- Direkt olarak zarar görülebilirlikle ilişkilidir.

- Toplumların baş edebilme kapasitesinin üzerindedir.

- Teknoloji ve doğayla alakalı bir durumun oluşmasından öte toplum ile ilgilidir. 
Tüm bunlar değerlendirildiğinde, afet kavramı insan ve çevre için kayıplar oluşturabilmekte ve insan yaşantısında gerek maddi gerekse sosyal kayıpların oluşmasına neden olabilmektedir. Ayrıca afetlerden sadece insanlar değil afetin yaşandığı bölgedeki tüm canlı populasyonu da etkilenebilmektedir. $\mathrm{Bu}$ nedenle afetler, ulusal kaynakların seferber olmasını gerektirmekte ve toplumsal olarak baş etmeyi ögrenmeye zorunlu tutmaktadır. Bu bağlamda afetler için yaşanan olayların kendisinin değil oluşturduğu sonuç olduğunu şeklinde ifade etmek doğru olacaktır (Erten, 2011).

Ülkemizde yaşanan doğal afetlerin başında depremler gelmektedir. Ülke nüfusunun büyük bir bölümünün deprem kuşağında yer alması ve depremlerin büyük ölçüde gerek can gerekse mal kayıplarına yol açabildiği için doğal afetler arasında en önemli olanlarından biri şeklinde de ifade edilebilir. Türkiye kuşak olarak, Alp-Himalaya deprem kuşağında yer almaktadır. Ülke içinde ise birçok aktif fay hattı bulunmaktadır. Ülkemizdeki fay hatlarının 1990 verilerine göre etkilediği nüfus incelendiğinde ise, yaklaşık \%44'ü birinci, \%26'sı ikinci, \%15'i üçüncü derece deprem bölgesinde yaşamaktadır. Bu verilere göre, Türkiye büyük bir bölümü deprem riski olan bölgelerde yaşamaktadır (Genç, 2007).

Doğal afetlerin olusmuz etkilerini arttırabilecek birçok neden bulunmaktadır. Hızlı nüfus artışı, iç ve dış göçler, doğal dengenin zarar görmesi, iklim değişikliği, küresel 1sınma, toplumun afet konusundaki eğitim düzeyinin zayıf olması, denetlemedeki zayıflıklar doğal olmayan afetlerin etkisini ve zararını daha da çok arttırmaktadır. Tüm bu olumsuzlukları kabul edilebilir sınırlar çerçevesinde kalabilmesi için etkin ve güçlü bir afet yönetim sisteminin kurulması zorunlu ve son derce elzemdir (Uzunçıbuk, 2005).

Afet yönetiminin başarılı olabilmesi bir plan oluşturulması ve halk için eğitim programlarının yaygınlaştırılmasına bağlıdır. Bu bağlamda afet yönetiminin temel hedefi, afetleri engellemek, oluştuğu anda ve sonraki süreçlerde etkisinden kısa sürede kurtulmak şeklinde açıklanabilir (Putra vd., 2011). Afet yönetimin bu temel hedefi çerçevesinde planların hazırlanıp, ulusal afet politikası şeklinde varlı̆̆ı ve kültürünün oluşturulması gerekmektedir. Maalesef ülkemizde afet yönetimi bir disiplin olarak görülmemektedir. Bu nedenle de modern bir afet yönetim anlayışı günümüzde kadar oluşmamıştır. Fakat geçmişi çok eski olan ve yeryüzü oluştuğundan bu yana süregelen afetler toplumları işlevsel ve uygulanabilir bir afet yönetimini oluşturmaya itmesi gerekmektedir. Ancak ülkemizde afetlerin engellenmesi veya zararlarının en az düzeyde olmasına imkan verecek yerel ve merkezi bir yönetimin olmayışı, devlet ve özel sektörün görev ve sorumluluklarını tam olarak yerne getirmemesi, etkin bir afet yönetim modelinin kurulamamasına neden olmuştur (Akdağ, 2011:2).

\section{Afet Yönetiminin Aşamaları}

Bazı durumlarda afetlerin engellenmesi imkansız olabilmektedir. Bundan dolayıdır ki afetin engellenmesi değil uyarı, afet oluşumundan haberdar olunması ve afet görüldükten sonra fiziki ve sosyal zararların engellenmesine çalışmak ya da tedbirler almak gerekir (Doğan, 2016). Günümüzde insan, doğa ve teknolojiden kaynaklı afetlerden sonra oluşabilecek zararların çevre sorunları, can ve mal kaybı açısından oldukça yıkıcı etkilerinin olacağını tahmin etmek çok da zor değildir. Bu zararların engellenmesi ve azaltılmasına yönelik olarak karşımıza gelen afet yönetimi terimi; olası bütün tehlikelere karşı hazırlıklı olma, zarar azaltma, iyileştirme ve müdahale etme maksadıyla eldeki tüm kaynakları düzenleyen; planlama, karara bağlama ve sonuçlandırma süreçlerinin tamamını içine alır. Bundan dolayı afet yönetimi çalışmalarının birlikte sürdürülmesi gerekmektedir (Kadığlu, 2008). Afet yönetim aşamalarını şu şekilde açıklamak mümkündür.

\section{Zarar azaltma}

Afet tehlike ve risklerinin engellenmesi veya büyük kayıplara neden olmaması için atılması gereken adımların ve yapılması planlanan çalışmaların bu aşamada gerçekleştirilmesi gerekmektedir. Normal dönemlerde, afetlerin oluşmasından evvel olası tüm kayıpları ile çevre sorunlarının çaplarına yönelik 
çalışmalar yapılmalı, riskler belirlenmeli ve bunlar analiz edilmelidir. Afet sırasında ve sonrasında gerçekleştirilecek müdahalenin stratejisi ve planlamasının yapılması, bu aşamanın önemini göstermektedir (Kaya, 2019). Zarar azaltma evresinin normal dönemlerde ya da afetlerde iyi hazırlanması, yaşanması muhtemel kayıpların engellenmesini ve afetlerin de önlenmesini sağlar (Şahin, 2007). Bu evrede yapılan hazırlıklar, yeniden inşaa evresindeki müdahalelerle başlamakta ve tekrar bir afet olana kadar devam etmektedir.

\section{Hazırlık}

Afet anında yetki ve sorumluluklarının belirlenmesi ile destek kaynaklarının düzenlenmesi, hazırlık evresidir. Genel olarak aniden meydana gelen afetlere hızlı ve etkin çözümler bulmak çok zordur. Afet meydana geldiği sirada, afete müdahale edecek olan birimlerin daha önceden belirlenen sorumluluklarını yerine getirmesi mümkündür. Tüm yönetim birimleri, afete müdahale edecek olan görevliler için gerekli çalışmaları yapmalı ve görevlilerin söz konusu müdahaleyi gerçekleştirebilmesi için gereken tüm bileşenleri tesis etmelidir. Donanım, ekipmanların tadilatı, erken uyarı ve tahmin sisteminin hazır tutulması, görevlilere eğitimler verilerek tüm sistemler güncel tutulmalıdır. Yönetim tarafından yapılan afet müdahale planlarının ve kaynakların olağanüstü dönemlerde zarar görmesinin engellenmesi ve bu planlara ilişkin risklerin ortadan kaldırılması için çalışmalar yapılması gerekir (Uzunçıbuk, 2005).

$\mathrm{Bu}$ evredeki çalışmaların temel hedefi; insanlar için olumsuz durumlara neden olacak tehlikelerin sonuçlarını, uygun yöntem ve önlemleri zamanında planlayarak ortadan kaldırmaktır. Buradaki çalışmalar afetlerin yıkıcı etkilerini azaltacak, insanların can ve mal güvenliğinin tesis edilmesi, farklı zaman dilimlerinde çok sayıda iş aşamalarını kapsayabilir. Bundan dolayı da zarar azaltma evresindeki çalışmalar ile aynı anda gerçekleşebilir. Örnek vermek gerekirse halkın muhtemel afetlere karşı hazırlıklı olması için halkın katılımının sağlanacağı geniş kapsamlı eğitim faaliyetlerinin düzenlenmesi, bunların sıklaştırılması, riskli alanların onarımı ve güçlendirilmesi çalışmaları gösterilebilir (Ergünay, 1999).

\section{Müdahale}

Afetin ardından hızlı ve etkin bir şekilde insan hayatını kurtarmak ve afetin neden olduğu diğer zararları en aza indirgemek, yaralıların ve barınma sorunu bulunanların ihtiyaçlarının karşılanması gibi amaçlar için yapılan çalışmaların tamamı müdahale evresi kapsamındadır. $\mathrm{Bu}$ aşamada gerçekleştirilecek faaliyetler, devletin sahip olduğu bütün güç ve kaynakların etkin ve hızlı bir şekilde afetin gerçekleştiği bölgede uygulanabilirliği ile mümkün olacaktır (Şahin, 2007). Müdahale evresi için çok iyi hazırlanan plan ve koordinasyona ihtiyaç bulunmakta ve olağanüstü durumlar için uygulanma zorunluluğu olan olağanüstü hazırlık ve yetki gerekmektedir. Bu evrede meydana gelen aksaklıklar afetin zararlarının artmasına neden olacaktır. Bundan dolayı müdahale evresinin uygulanabilir olması çok önemlidir. $\mathrm{Bu}$ evre, bir plan ve düzen için olmalıdır. Önceden hazırlanan bir planın veya düzenlemenin olmadığı hallerde, toplumda kargaşa çıkacaktır. Bu kargaşa ise müdahale evresinin başarısızlıkla sonuçlanmasına neden olacaktır (Kaya, 2019).

\section{Iyileştirme}

Afete uğramış toplulukların normal yaşama dönmesi amacıyla yapılan iletişim, eğitim, ulaşım, geçici veya uzun süreli konaklama, su, elektrik, kanalizasyon, sosyo ekonomik faaliyetler gibi insan yaşamında önemli bir yeri olan aktivitelerin olabilen en kısa sürede, en alt seviyede olsa dahi karşılanması gereken aşama, iyileştirme evresi olarak ifade edilir (Şengün ve Temiz, 2007). Ayrıca söz konusu işlemlerin sadece insanların yaşamını devam ettirmesini sağlamak amacıyla yapıldığını değil, aynı zamanda bir sonraki afet için de bir tür hazırlık olduğunun bilinmesi gerekir. Toplumun güvenli bir şekilde hayatını devam ettirmesi için söz konusu çalışmaların sürekliliği çok önemlidir. Bu evredeki çalışmalar, afetin büyüklüğüne göre farklılık gösterir. 
Alan yazına göre konu ile ilgili yapılan çalışmalar (Öcal, Çakır ve Özelmacı, 2016; Kiraz, 2018; Kaya, 2019; Köseoğlu, 2019) çoğunlukla öğrenci pozisyonundaki kişiler ve halk ile ilgilidir. Ayrıca yapılan literatür taramalarına göre afet yönetimini öğretim elemanları üzerinde test eden bilgi ve beceri düzeylerini çeşitli değişkenler açısından ölçen, güvenirliliği ve geçerliliği olan bir çalışmanın eksikliği görülmüştür. Buna göre, araştırmanın problemini, öğretim elemanlarının afet yönetimi ile ilgili hazırlık düzeylerini ortaya çıkarmak ve üniversitelerde görev yapan bireylerin karşılaştırmalı analizlerle bilgi, tutum ve davranış düzeylerinin incelenmesidir.

$\mathrm{Bu}$ çalışmanın amacı üniversite personelinin afet ve acil durumlarla karşılaşması durumundaki bilgi tutum ve davranışlarının ölçülmesini amaçlamaktadır. Araştırmanın genel amacı dahilinde diğer alt problemlere de cevap aramaya çalışılmıştır:

1. Üniversite personelinin afetlere hazırlık düzeyleri (bilgi, tutum ve davranış boyutunda), eğitim düzeylerine göre anlamlı farklılık göstermekte midir?

2. Üniversite personelinin afetlere hazırlık düzeyleri (bilgi, tutum ve davranış boyutunda), daha önce afete maruz kalma durumuna göre anlamlı farklılık göstermekte midir?

3. Üniversite personelinin afetlere hazırlık düzeyleri (bilgi, tutum ve davranış boyutunda), akademik ve idari personel oluşuna göre anlamlı farklılık göstermekte midir?

\section{Yöntem}

$\mathrm{Bu}$ çalışma mevcut olan bir durumu olduğu gibi ortaya koyabilmek maksadıyla tarama modelinde tasarlanmıştır. Genel tarama modeli, fazla sayıda kişinin bir araya gelmesiyle oluşturulan evrende, evrenin genel hatları hakkında genel bir yargıya varmak amacıyla, evreni oluşturan tüm bireyleri üzerinde yapılacak olan tarama yöntemleridir (Karasar, 2005: 81).

\section{Örneklem}

Çalışmanın başlangıç takvimi 2018 verilerine göre 2491 olan tüm evren sayısından 1693 kişiye (örneklem) ulaşılmıştır. Araştırmanın tüm evrene göre elde edilen veri \% 68 olarak gerçekleştirilmiştir. Araştırmanın evreni 2018 verilerine göre tablo 1'deki gibidir.

Tablo 1. Araştırma Evreni

\begin{tabular}{lcc}
\hline & Evren & Ulaşılabilen \\
\hline Profesör & 203 & 83 \\
Doçent Doktor & 189 & 156 \\
Doktor Öğretim Üyesi & 518 & 352 \\
Öğretim Görevlisi & 413 & 349 \\
Araştırma Görevlisi & 405 & 252 \\
İdari Personel & 763 & 501 \\
Toplam & 2491 & 1693 \\
\hline
\end{tabular}

\section{Veri Toplama Aracı}

Verilerin elde edilmesi sürecinde gönüllü olan bireylerden yüz yüze veri toplama yöntemi seçilmiştir. Ölçeğin ilk kısmında üniversitede görev yapan akademik ve idari personelin, acil durum ve afet yönetimi konusunda tutumlarını etkilemesi muhtemel; yaşı, cinsiyeti, eğitim düzeyi, afet yönetimiyle alakalı eğitim alma değişkenine yönelik maddeler bulunmaktadır. İkinci bölümde ise, üniversite personelinin acil durum ve afet yönetimine ilişkin tutumlarını belirlemek amacıyla Kiraz'ın (2008: 97) tezinde kullanmış olduğu; 5'li likert tipinde 3 alt boyuttan ve 38 sorudan oluşan "Afet ve Acil Durum Hakkında Bilgi, Tutum ve Davranış Ölçeği” kullanılmıştır. 
Ölçeğin alt boyutları şu şekildedir; Afet ve acil durumlara hazırlık bilgi, tutum ve davranış boyutudur. Ölçek 38 maddeden oluşmaktadır ve iç tutarlık katsayısı, 0,92 olarak rapor edilmiştir. Bu araştırma kapsamında, ölçeğin yapı geçerliği ve güvenirliğine ilişkin olarak aşağıdaki kanıtlar elde edilmiştir. Ölçeğin iç tutarlığına ilişkin olarak elde edilen Cronbach Alpha katsayısı, bilgi alt boyutu için 0,88 , tutum için 0,70 ve davranış alt bıyutu için 0,89 olarak hesaplanmıştır. Ölçeğin tümü için ise Cronbach Alpha iç tutarlık katsayısı 0,91 olarak bulunmuştur. Ölçeğin yapı geçerliğini incelemek amacıyla model-veri uyumu incelenmiş olup, bu kapsamda doğrulayıcı faktör analizi (DFA) yapılmıştır. DFA analizine ilişkin olarak, Comperative Fit Index (Karşılaştırmalı Uyum İndeksi CFI), Goodnessof-fit Index (Uyum İyiliği Endeksi, GFI), Incremental Fit İndex (Artan Uyum İndeksi, IFI), Normed Fit Index (Normlaştırılmış Uyum İndeksi, NFI), Normlaştırılmamış Uyum Endeksi) (Non-Normed Fit İndex, NNFI), Serbestlik Derecesinden Arındırılmış GFI(Adjusted Goodness of Fit Index, AGFI) ve Yaklaşık Hataların Ortalama Karekökü (Root Mean Square Error of Approximation, RMSEA) değerleri incelenmiştir. Ölçeğe ilişkin DFA sonuçları Tablo 2'de verilmiştir.

Tablo 2. DFA Sonucundan Elde Edilen Uyum Değerleri

\begin{tabular}{lllcl}
\hline Uyum İndeksi & Mükemmel & Kabul Edilebilir & Elde Edilen Değerler & \multicolumn{1}{c}{ Uyum } \\
\hline$\chi 2 /$ sd & $0 \leq \chi 2 / \mathrm{sd} \leq 2$ & $2 \leq \chi 2 / \mathrm{sd} \leq 3$ & 8,55 & Kabul edilebilir değil \\
GFI & $, 95 \leq \mathrm{GFI} \leq 1,00$ &, $90 \leq \mathrm{GFI} \leq, 95$ &, 90 & Kabul edilebilir \\
CFI & $, 95 \leq \mathrm{CFI} \leq 1,00$ &, $90 \leq \mathrm{CFI} \leq, 95$ &, 90 & Kabul edilebilir \\
IFI & $, 95 \leq \mathrm{IFI} \leq 1,00$ &, $90 \leq \mathrm{IFI} \leq, 95$ &, 90 & Kabul edilebilir \\
NFI & $, 95 \leq \mathrm{NFI} \leq 1,00$ &, $90 \leq \mathrm{NFI} \leq, 95$ &, 90 & Kabul edilebilir \\
NNFI &, $97 \leq \mathrm{NNFI} \leq 1.00$ &, $95 \leq \mathrm{NNFI} \leq, 97$ &, 90 & Kabul edilebilir \\
AGFI &, $90 \leq \mathrm{AGFI} \leq 1.00$ &, $85 \leq \mathrm{AGFI} \leq, 90$ &, 82 & Kabul edilebilir değil \\
RMSEA & $0 \leq \mathrm{RMSA} \leq 0,05$ & $0,05 \leq \mathrm{IFI} \leq 0,08$ &, 06 & Kabul edilebilir \\
\hline
\end{tabular}

Tablo 2'de, alan yazında (Schermelleh-Engel vd., 2003: 23) önerilen uyum değerleri ile araştırmada kullanılan ölçeğin uyum değerleri karşılaştırılmıştır. Tabloda uyum indeksleri incelendiğinde, GFI, CFI, IFI ve NFI uyum indekslerinin kabul edilebilir uyum gösterdiği bulunmuştur. GFI, AGFI, DFA sonuçlarına istinaden, hem $\chi^{2} / \mathrm{sd}$, hem de geri kalan verilere göre değerlendirildiğinde çalışmanın üç alt boyutlu olarak iyi uyum gösterdiği, buna bağlı olarak çalışmanın üç alt boyutlu olarak ölçülebileceği söylenebilir.

\section{Verilerin Analizi}

Verilerin normal dağılımını test etmek amacıyla Shapiro-Wilks testi sonucu elde edilen p değerine, çarpıklık ve basıklık katsayılarına bakılmış ve dağılımın normalliği konusunda karar verilmiştir.

Üniversite personelinin afetlere hazırlık düzeyleri (bilgi boyutunda), eğitim düzeylerine göre yapılan analizler için; veriler üzerinde yapılan analizler öncelikle her bir alt problem için veri analizindeki varsayımları karşılayıp karşılamadığı incelenmiş ve buna dayalı olarak da parametrik ve parametrik olmayan testlerden faydalanılarak veri analizi gerçekleştirilmiştir. Verilerin normal dağılımını sınamak amacıyla çarpıklık ve basıklık katsayılarına bakılmış ve dağılımın normalliği konusunda karar verilmiştir. Çarpıklık ve basıklık değerlerinin \pm 1.50 aralığında olması, verilerin normal dağıldığına işaret etmektedir(Büyüköztürk, 2005). Bu bağlamada, araştırmadaki alt problemleri yanıt vermek amaciyla tek yönlü varyans analizi (one way anova), t-testi ve mann whitney u testleri kullanılmıştır. 


\section{Bulgular}

$\mathrm{Bu}$ bölümde araştırmanın alt amaçlarına yönelik olarak verilerden elde edilen bulgulara yer verilmiştir.

Araştırmanın ilk alt amacı olan "Üniversite personelinin afetlere hazırlık düzeyleri (bilgi, tutum ve davranış boyutunda), eğitim düzeylerine göre anlamlı farklılık göstermekte midir" sorusuna yanıt vermek amacıyla tek yönlü varyans analizi yapılmış ve elde edilen buglular Tablo 3 'te verilmiştir.

Tablo 3. Eğitim Düzeylerine Göre Afetlere Hazırlık Bilgi Düzeylerine İlişkin ANOVA Testi

\begin{tabular}{lcccccc}
\hline Varyansın Kaynağı & $\begin{array}{c}\text { Kareler } \\
\text { toplamı }\end{array}$ & $\begin{array}{c}\text { Serbestlik } \\
\text { Derecesi }\end{array}$ & $\begin{array}{c}\text { Kareler } \\
\text { Ortalaması }\end{array}$ & F & P & Anlaml fark \\
Gruplar arası & 25,823 & 4 & 6,45 & 17,13 &, 00 & Lisans-önlisans \\
& & & & & & Lisans-yükseklisans \\
Grup içi & 644,012 & 1709 & 0,37 & & Lisans-doktora \\
Toplam & 669,834 & 1713 & & & \\
\hline
\end{tabular}

Katılımcıların eğitim düzeylerine göre afetlere hazırlık bilgi düzeylerine ilişkin Anova sonuçları incelendiğinde, ortalamaları kıyaslanan gruplar arasında birden fazla grup ortalamasının farklı olduğu tespit edilmiştir [Brown-Forsthe ${ }_{(4-1709)}=17,13, \mathrm{p}<, 05$ ]. Levene varyans eşitliği testine göre verilerin homojen dağılım göstermediği bulunmuştur. Bu yüzden Anova testinde ortaya çıkan anlamlı düzeydeki farkları belirlemek için çoklu karşılaştırma yöntemlerinden Dunnett's testine göre analiz yapılmıştır. Çıkan sonuçlara göre, lisans düzeyinde eğitim almış olan personelin afete hazırlık bilgi düzeyi ortalamas1 $(\bar{X}=2,91)$, ön lisans $(\bar{X}=2,60)$ ve doktora $(\bar{X}=2,78)$ düzeyinde eğitim almış olan personelden daha yüksektir.

Tablo 4. Eğitim Durumuna Göre Afet Anı Davranış Durumuna İlişkin Puan Ortalamaları

\begin{tabular}{lccc}
\hline \multicolumn{1}{c}{ Eğitim Durumu } & $\mathrm{N}$ & Ortalama & Standart sapma \\
\hline Lise & 73 & 2,57 &, 65 \\
Ön Lisans & 149 & 2,60 &, 71 \\
Lisans & 319 & 2,91 &, 59 \\
Yüksek Lisans & 527 & 2,58 &, 53 \\
Doktora & 646 & 2,78 &, 59 \\
Toplam & 1714 & 2,69 &, 59 \\
\hline
\end{tabular}

Tablo 4'deki ortalamalara bakıldığında lisans eğitim durumu davranış düzeyi $(\bar{X}=2,91)$, ön lisans eğitim durumu davranış düzeyinden $(\bar{X}=2,60)$ daha yüksektir. Doktora eğitim durumu davranış düzeyi $(\bar{X}=2,78)$, yüksek lisans eğitim durumu davranış düzeyinden $(2,58)$ daha yüksek olduğu bulunmuştur.

\section{Tablo 5. Eğitim Durumuna Göre Afet Anı Davranış Durumuna İlişkin ANOVA Testi}

\begin{tabular}{lccccccc}
\hline Kareler toplamı & & $\begin{array}{c}\text { Serbestlik } \\
\text { Derecesi }\end{array}$ & Kareler Ortalaması & F & P & Anlamlı fark \\
\hline Gruplar içi & 14,43 & 4 & 3,61 & 10,32 &, 00 & Lisans-önlisans \\
& & & & & & Lisans-yükseklisans \\
Gruplar aras & 597,25 & 1709 & 0,34 & & & Lisans-doktora \\
Toplam & 611,69 & 1713 & & & & \\
\hline
\end{tabular}


Katılımcıların eğitim düzeylerine göre afet anı davranış durumlarına ilişkin anova sonuçları incelendiğinde, ortalamaları kıyaslanan gruplar arasında birden fazla grup ortalamasının farklı olduğu tespit edilmiştir [Brown-Forsthe ${ }_{(4-1709)}=10,32, \mathrm{p}<.05$ ]. Levene varyans eşitliği testine göre verilerin homojen dağılım göstermediği bulunmuştur. Bu yüzden Anova testinde ortaya çıkan anlamlı düzeydeki farkları belirlemek için çoklu karşılaştırma yöntemlerinden Dunnett's C testine göre analiz yapılmıştır. Buna göre, doktora düzeyinde eğitim almış olan personelin afet anı davranış düzeyi ortalamasının $(\bar{X}=2,78)$, lisans $(\bar{X}=2,75)$ ve önlisans $(\bar{X}=2,60)$ düzeyinde eğitim almış olan personellerin afet anı davranış düzeyi puan ortalamasından anlamlı bir şekilde farklılık gösterdiği bulunmuştur.

Tablo 6. Daha Önce Afete Maruz Kalma Durumuna Göre Afetlere Hazırlık Tutum Düzeyi Mann Whitney U testi Sonuçları

\begin{tabular}{llllll}
\hline Gruplar & $\mathrm{N}$ & $\begin{array}{l}\text { Siralar } \\
\text { Ortalamasi }\end{array}$ & $\begin{array}{l}\text { Siralar } \\
\text { Toplamı }\end{array}$ & $\mathrm{U}$ & $\mathrm{P}$ \\
\hline Evet & 307 & 813,20 & 249652,00 & 202374,00 &, 07 \\
Hayır & 1407 & 867,17 & 1220103,00 & & \\
Toplam & 1714 & & & \\
\hline
\end{tabular}

Daha önce afet yaşayan ve yaşamayan kişilerden oluşan grupta, afet yaşayan ve yaşamayan kişilerin afete hazırlık tutum düzeylerinin farklı olup olmayışını belirlemek amacıyla yapılan non-parametrik test Mann-Whitney U sonucuna göre, afete maruz kalan ile afete maruz kalmayan personel arasinda anlamlı düzeyde farkın olmadığı tespit edilmiştir (U=202374,00, p>,05). Buna göre; katılımcıların daha önce afete maruz kalıp kalmamalarının afete hazırlık tutum puanları açısından bir fark oluşturmadığ 1 söylenebilir.

Afet anı davranış düzeyinin daha önceden afete maruz kalıp kalmamaya ilişkin yapılan $t$ testi sonuçları Tablo 7 de verilmiştir.

\section{Tablo 7. Afet Anı Davranış Düzeyine İlişkin Bağımsız t Testi Sonuçları}

\begin{tabular}{lllllll}
\hline Afete maruz kalma Durumu & N & Ortalama & $\begin{array}{l}\text { Standart } \\
\text { Sapma }\end{array}$ & $\begin{array}{l}\text { Serbestlik d } \\
\text { derecesi }\end{array}$ & T \\
\hline Evet & 307 & 3,02 & 0,69 & 393,56 & 0,58 & 9,68 \\
Hayır & 1407 & 2,61 & 0,54 & & & \\
\hline
\end{tabular}

Personelin daha önce afete maruz kalma durumuna göre afet anı davranış düzeyleri $t$ testi sonuçlarına göre anlamlı fark bulunmuştur $(\mathrm{t}(393,56)=9,68, \mathrm{p}>, 05)$. Buna göre, daha önce afete maruz kalan bireylerin afet anı davranış puan ortalamaları $(\bar{X}=3,02)$, maruz kalmayanlara göre $(\bar{X}=2,61)$ daha yüksektir. Bu bağlamda, araştırmaya katılan ve daha önceden afete maruz kalan bireylerin afet anında daha bilinçli oldukları söylenebilir.

Tablo 8. Afetlere Hazırlık Bilgi Düzeyleri t Testi Sonuçları

\begin{tabular}{|c|c|c|c|c|c|c|c|c|}
\hline & $\begin{array}{l}\text { Personel } \\
\text { durumu }\end{array}$ & $\mathrm{N}$ & Ortalama & $\begin{array}{l}\text { Standart } \\
\text { Sapma }\end{array}$ & $\begin{array}{l}\text { Serbestlik } \\
\text { Derecesi }\end{array}$ & $\mathrm{d}$ & $\mathrm{t}$ & $\mathrm{P}$ \\
\hline Afete hazırlık bilgi düzeyi & Akademik & 1192 & 2,66 & 0,58 & 851,05 & 0,29 & 5,95 & 0,00 \\
\hline Afete hazırlık bilgi düzeyi & İdari & 501 & 2,87 & 0,69 & & & & \\
\hline
\end{tabular}


Akademik ve idari personelin afetlere hazırlık bilgi düzeyleri t testi sonuçları incelendiğinde anlamlı düzeyde farkın bulunduğu tespit edilmiştir $\left(\mathrm{t}_{(851,05)}=5,95, \mathrm{p}<, 05\right)$. Bu bulguya göre, afete hazırlık bilgi düzeyi açısından akademik personel ortalaması $(\bar{X}=2,66)$, idari personelin ortalamasından $(\bar{X}=2,87)$ daha düşüktür. Bir başka ifadeyle, akademik personelin afete hazırlık bilgi düzeylerinin daha düşük olduğu söylenebilir.

Tablo 9. Afet Anı Davranış Durumuna İlişkin t Testi Sonuçları

\begin{tabular}{llllllll}
\hline Personel durumu & $\mathrm{N}$ & Ortalama & $\begin{array}{l}\text { Standart } \\
\text { sapma }\end{array}$ & $\begin{array}{l}\text { Serbestlik } \\
\text { Derecesi }\end{array}$ & $\mathrm{d}$ & $\mathrm{t}$ & $\mathrm{P}$ \\
\hline Akademik & 1465 & 2,66 & 0,56 & & & & \\
İdari & 501 & 2,73 & 0,65 & 870,76 & 1,02 & 1,98 & 0,00 \\
\hline
\end{tabular}

Akademik ve idari personelin afet anı davranış düzeylerine ilişkin t testi sonuçları incelendiğinde anlamlı düzeyde farkın bulunduğu tespit edilmiştir $(\mathrm{t}(870,76)=1,98, \mathrm{p}<, 05)$. İdari personelin afet anı davranış düzeyi ortalaması $(\bar{X}=2,73)$ akademik personelin afet anı davranış düzeyi ortalamasından $(\bar{X}=2,66)$ daha yüksek bulunmuştur. Buna göre idari personelin afet anı davranış düzeyinin akademik personelin afet bilgi düzeyinden daha fazla olduğu söylenebilir.

Tablo 10. Afet Eğitimi Alma Durumuna Göre Afetlere Hazrlık Bilgi Düzeyleri t Testi

\begin{tabular}{llllllll}
\hline Eğitim Alma Durumu & $\mathrm{N}$ & Ortalama & $\begin{array}{l}\text { Standart } \\
\text { Sapma }\end{array}$ & $\begin{array}{l}\text { Serbestlik d } \\
\text { derecesi }\end{array}$ & $\mathrm{t}$ & $\mathrm{p}$ \\
\hline Evet & 695 & 3,17 & 0,5 & 17,12 & 1,22 & 30,58 & 0 \\
Hayır & 1019 & 2,42 & 0,49 & 11,22 & & & \\
\hline
\end{tabular}

Peronelin eğitim alma durumuna göre afetlere hazırlık bilgi düzeyleri t testi sonuçlarına bakıldığında anlamlı düzeyde fark tespit edilmiştir $\left(\mathrm{t}_{(1712)}=30,58, \mathrm{p}<, 05\right)$. Etki değeri ise 1,22 dir. Çıkan sonuca göre, afet eğitimi alan bireylerin ortalamaları $(\bar{X}=3,17)$, afet eğitimi almayan bireylerin ortalamalarından $(\bar{X}=2,42)$ daha yüksek olduğu bulunmuştur. Böylece afet eğitimi alan kişilerin bilgi düzeyleri hiç eğitim almayan kişilerin bilgi düzeyinden daha yüksek olduğu söylenebilir. 


\section{Sonuç, Tartışma ve Öneriler}

Yapılan bu araştırmada üniversite personelinin afet yönetimi konusunda bilgi, tutum ve davranışları incelenmiş̧tir. Araştırmadan elde edilen betimsel sonuçlara göre, üniversite personelinin afetlere hazırlık bilgi düzeyinin orta düzeyde $\left(X^{-}=2,72\right)$ olduğu ortaya çıkmıştır. Buna benzer bir çalışma olan ve 2014 yılında Erzincan'da yapılan araştırma sonucunda da kişilerin afete hazırlık bilgi düzeylerinin yetersiz olduğu tespit edilmiştir (Polat, 2014). Bu sonuca göre, her yıl afet yaşanan ülkemizde bu seviyenin yeterli olmadığı söylenebilir. Çalışmaya katılan personellerden; akademik ve idari personelin afetlere hazırlık bilgi düzeyleri arasında anlamlı derecede bir fark bulunmuş olup, idari personelin bilgi seviyesinin $\left(X^{-}=2,87\right)$ akademik personel bilgi seviyesinden $\left(X^{-}=2,66\right)$ daha fazla olduğu sonucuna varılmıştır. Çelebi'nin (2014) yaptığı çalışmada lise mezunu olan personelin depremlere ilişkin bilgi düzeylerinin daha yüksek olduğu sonucu ortaya çıkmıștır. Afetlere hazırlık bilgi seviyesinin öğrenim durumlarına göre bir farkının olup olmadığına bakıldığında; en yüksek bilgi seviyesinin lisans $\left(\mathrm{X}^{-}=2,75\right)$ öğrenim durumunda olduğu tespit edilmiş, en düşük ise yüksek lisans $\left(X^{-}=2,58\right)$ öğrenim seviyesindeki personellerin oluşturduğu sonucuna varılmıştır. Yine yapılan benzer bir çalışmada lise mezunu olan personelin depremlere karşı hazırlık seviyelerinin daha yüksek olduğu ortaya çıkmıştır (Çelebi, 2014). Türkiye özelinde yapılan çalışmada ise öğrenim seviyesinin yükselmesiyle kişilerin bilinçlilik seviyesinde bir artışın olduğu sonucuna varılmıştır (AFAD, 2014b: 65). Afet eğitimi alan ve almayan üniversite personelinin afetlere hazırlık bilgi düzeyine bakıldığında ise, afet eğitimi alan kişilerin bilgi düzeyleri hiç eğitim almayan kişilerin bilgi düzeyinden daha yüksek olduğu ortaya çıkmıştır. Gümüşhane de yapılan bir çalışmada afet eğitimi alan kişilerin bilgi seviyelerinde pozitif yönde bir artışın oluşmasını sağladığı sonucuna varılmıştır (İnal vd., 2012: 15-20).

Daha önce afet yaşayan ya da yaşamayan kişilerin tutum düzeyi arasında fark olup olmadığ 1 araştırılmış ve anlamlı bir fark bulunmamıştır. Yapılan bir araştırmaya göre afete maruz kalan kişilerin afet eğitimlerine daha fazla katılım gösterdikleri ve evlerinde ilk yardım çantası bulundurma oranının daha fazla olduğu ortaya çıkmıştır (Ünal vd., 2017: 71-80). AFAD'ın (AFAD, 2014b: 67) yapmış olduğu bir çalışmada herhangi bir afete uğrayan kişilerin yaklaşık yarısının yaşadıkları bu olayın afet konusunda bilinçlenmelerine yardımcı olduklarını düşünmektedir. Yine benzer bir sonuç ise, afete maruz kalan öğretmenlerin afet eğitimine katılım oranlarının daha fazla olduğu sonucuna varılmıştır (Sarı, 2016). Buna göre afete maruz kalmanın kişilerin afetlere hazırlık tutum düzeylerini arttırdığı sonucuna ulaşılabilir. $\mathrm{Bu}$ araştırmada üniversite personelinin afet anı davranış düzeylerine ilişkin puan ortalamaları 2,66 olarak ortaya çıkmıştır. Bu orana göre personellerin davranış düzeyi orta seviyededir. Üniversite de görevli akademik ve idari personelin afet anı davranış durumları kıyaslandığında, akademik personelin davranış düzeyinin daha az olduğu ortaya çıkmıştır. Benzer bir sonucun, hastanede görevli doktora eğitim düzeyinde olan hemşirelerin diğer eğitim seviyesindekilere göre afetlere hazırlık düzeylerinin daha düşük olduğu ortaya çıkmıştır (Özcan, 2013).

Akademik ve idari personelin öğrenim durumuna ilişkin afet anı davranış durumları incelendiğinde en yüksek seviyenin doktora düzeyinde öğrenim görmüş kişilerin olduğu saptanmıştır. Benzer bir durumun AFAD'ın (2014b: 101) gerçekleştirmiş olduğu araştırmada da ortaya çıkmıştır. Buna göre eğitim seviyesinde ki artışın afetlere hazırlıklı olma seviyesini arttırdığı tespit edilmiştir. Yine bu çalışma sonuçlarına göre daha önce afete maruz kalan kişilerin afet anı davranış düzeylerinin daha yüksek olduğu saptanmıştır. Hoffmann ve Muttarak (2017: 50) tarafından ülkede yaptıkları (Tayland ve Filipinler) çalışmada, afete maruz kalan kişilerin afetlere yapılan hazırlık ve afet anında ki davranışları arasında olumlu yönde bir artışın gerçekleştiğini tespit etmişlerdir. AFAD’ın (2014a: 76) Türkiye'de yaptığı çalışmada afet yaşamış kişilerin bu konuda bilgi seviyelerinde bir artışın gözlemlendiğini ortaya çıkarmıştır. Yapılan bu çalışmada da buna benzer bir sonucun çıktığı kabul edilebilir. 


\section{Kaynakça}

AFAD (2014a). Açıklamalı afet yönetimi terimleri sözlüğ̈̈. Erişim adresi : [https://www.afad.gov.tr/Dokuman/TR/101-2014112716301-sozluk.pdf]. Erişim tarihi: 08.09.2020

AFAD; (2014b), Türkiye afet farkındalı̆̆ ve afetlere hazırlı araştırması. Erişim: https://www.afad.gov.tr/upload/Node/3923/xfiles/turkiye-afet-farkindaligi-veafetlere-hazirlikarastirmasi_-2014-edited.pdf,

Akdağ, R. (2011). T.C. Să̆llk bakanlı̆̆ı 2012 mali yılı Bütçesi’nin T.B.M.M. plan ve bütçe komisyonu'na sunumu, 23 Kasım 2011. http://www.saglik.gov.tr/TR/belge/114495/saglikbakanligi-2012-mali-yili-butce-sunumu, Erişim Tarihi: 20.09.2019.

Büyüköztürk, Ş. (2005). Sosyal bilimler için veri analizi el kitabı. Ankara: PegemA

Çelebi, İ. (2014). Kayseri 112 Acil Sağllk Hizmetlerinde Görev Yapan Sağllk Personelinin Deprem Bilgi Düzeyi, Depreme Hazırlık Durumu ve Etkileyen Etmenler. (Yayımlanmamış yüksek lisans tezi). Dokuz Eylül Üniversitesi, Sağlık Bilimleri Enstitüsü, İzmir.

Doğan, B. (2016). Afet riski nedeniyle kentsel dönüşüm: İzmir örneği. Adnan Menderes Üniversitesi Sosyal Bilimler Enstitüsü Siyaset Bilimi ve Kamu Yönetimi Anabilim Dalı, Yayımlanmamış Yüksek Lisans Tezi, Aydın

Ergünay, O. (1999). Acil yardım planlaması ve afet yönetimi. Uzman Der Dergisi, 2,(6-7), , 11

Erten, İ. (2011). Türk kamu yönetiminde kriz yönetimi anlayışı. (Yayınlanmış yüksek lisans tezi), Süleyman Demirel Üniversitesi, Isparta

Genç, F. N. (2007). Türkiye'de doğal afetler ve doğal afetlerde risk yönetimi, Stratejik Araştırmalar Dergisi, 5(201-226).

Hoffmann, R. and Muttarak, R. (2017). Learn From The Past, Prepare For The Future: Impacts Of Education And Experience On Disaster Preparedness İn The Philippines And Thailand, World Development, 96, 32-51.

İnal, E., Kocagoz, S. ve Turan, M. (2012). Basic Disaster Consciousness and Preparation Levels/Temel Afet Bilinc ve Hazirlik Duzeyinin Saptanmasina Yonelik Bir Arastirma. Turkish Journal of Emergency Medicine, 12(1), 15-20.

Kadığlu, M. (2008). Afet zararlarını azaltmanın temel ilkeleri. Ankara: JICA Türkiye Ofsi,

Kadığlu, M. ve Özdamar, E. (2011). Afet Yönetimi Beklenilmeyeni Beklemek, En Kötüsünü Yönetmek. Ankara: T.C. Marmara Belediyeler Birliği Yayını, 56, 121-128.

Karasar, N. (2005). Bilimsel araştırma yöntemi, Ankara: Nobel Yayıncılık.

Kaya, N. (2019). Ülkemizdeki bulaşıcı hastalık bildirimlerinin afet yönetimi açısından incelenmesi. Yüksek Lisans Tezi. Gümüşhane Üniversitesi Sosyal Bilimler Enstitüsü, Gümüşhane

Kemaloğlu, M. (2015). Türkiye'de Afet Yönetiminin Tarihi ve Yasal Gelişimi. Akademik Baklş Dergisi, 52, 126-147.

Kiraz, E. (2018). Afet ve Acil Durum Hakkında Bilgi, Tutum ve Davranışların Değerlendirilmesi: Sakarya ve Konya İli Örneği. (Yüksek Lisans Tezi). Gümüşhane Üniversitesi Sosyal Bilimler Enstitüsü, Gümüşhane.

Köseoğlu, S. (2019). Acil Yardim Ve Afet Yönetimi Bölümü Öğrencilerinin Akademik Risk Alma Ĕ̆ilimleri Ve Liderlik Özelliklerinin Belirlenmesi Kriz Ve Kaos Yönetimi Çerçevesinde Değerlendirilmesi; Çanakkale Onsekiz Mart Üniversitesi Örneği. (Yüksek Lisans Tezi). Çanakkale Onsekiz Mart Üniversitesi ,Eğitim Bilimleri Enstitüsü, Ankara. 
Öcal, A. , Çakır, U. \& Özelmacı, Ş. (2016). İlkokul ve Ortaokul Ders Programlarında Afetten Korunma ve Güvenli Yaşam. Alan Eğitimi Araştırmaları Dergisi, 2(2), 71-83.

Özcan, F. (2013). Hemşirelerin Afete Hazır Olma Durumu ve Hazırlık Algısı. (Yayımlanmamış yüksek lisans tezi). Marmara Üniversitesi, Sağlik Bilimleri Enstitüsü, İstanbul.

Polat, T. (2014). Erzincan Yavuz Selim Mahallesinde İkamet Eden Ulaşılabilen 18 Yaş ve Üstü Bireylerin Temel Afet Bilinci Bilgi Düzeylerinin Saptanması. (Yüksek Lisans Tezi). Gazi Üniversitesi ,Sağlık Bilimleri Enstitüsü, Ankara.

Putra, A., Petpichetcian, W. ve Manewat K. (2011). Rewiew: public health nurses' roles and competencies in disaster management. Nurse media journal of nursing, 1(1): 1-14.

Sarı, B. (2016). Türkiye'de Afet Eğitimi Uygulamalarının Öğretmen Görüşleri Açısından Değerlendirilmesi. (Yayımlanmamış yüksek lisans tezi). Çanakkale Onsekiz Mart Üniversitesi, Eğitim Bilimleri Enstitüsü, Çanakkale

Schermeller-Engel, K. , Moosbrugger, H. (2003). Evaluating the Fit Of Scructural Equation Models: Test Of Significance and Descriptive Goodness-Of-Fit Measures. Methods of Psychological Resarc - Online, 8(2), 23-74.

Şahin N. (2007). Afet yönetimi ve acil yardım planları. TMMOB Kent Sempozyumu, 2007, 134. Ankara

Şahin, C. ve Sipahioğlu, İ. (2002). Doğal afetler ve Türkiye. Ankara: Gündüz Yayınevi

Şengün, H. ve Temiz A. (2007). Afet yönetimi ve Karabük, TMMOB Afet Sempozyumu, 6. ТMМOB Mimarlar Odası İstanbul Büyük Kent Şubesi, İstanbul.

Türk Dil Kurumu, 2020. Güncel Türkçe sözlük. Erişim adres: https://sozluk.gov.tr/ Erişim tarihi: 10.09.2020

Uzunçıbuk, L. (2005). Yerleşim yerlerinde afet ve risk yönetimi. Ankara: Pegem

Ünal, S. ve Dımşıkı, E. (1999). UNESCO-UNEP Himayesinde Çevre Eğitiminin Gelişimi ve Türkiye' de Ortaöğretim Çevre Eğitimi. Hacettepe Üniversitesi Eğitim Fakültesi Dergisi, 16(16-17), 142-154.

Ünal, Y., Işık, E., Şahin, S. ve Tekeli, Y. S. (2017). Sağlık Afet Çalışanlarının Depremlere İlişkin Bireysel Hazırlık Düzeylerinin Değerlendirilmesi: Ulusal Medikal Kurtarma Ekipleri (UMKE) Derneği Örneği. DEÜ Tip Fakültesi Dergisi, 31(2), 71-80. 